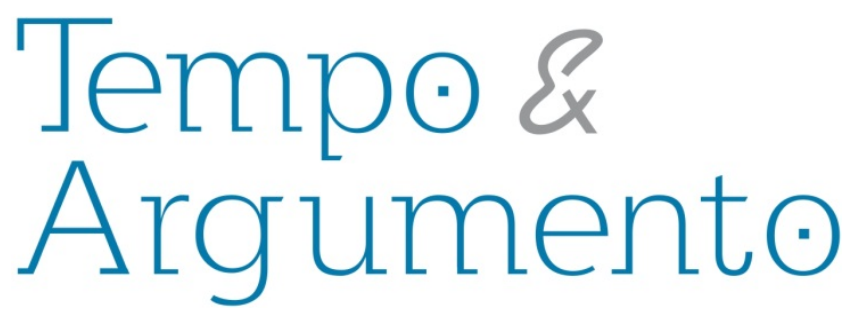

\title{
Reescrevendo a história: imigrantes italianos, colonos alemães, portugueses e a população brasileira no sul do Brasil ${ }^{1}$
}

\begin{abstract}
Resumo
Visamos entender como a criação de identidades étnicas, produzidas pela imigração, dividem o mundo entre "nós" e os "outros". Analisaremos como esse "nós" pode ser relacional e em alguns momentos abarcar os "outros" tendo, como suporte empírico, os descendentes dos imigrantes europeus no Rio Grande do Sul. Como método de trabalho, utilizamos a etnografia e a pesquisa histórica, com a história política e econômica para entender as transformações nas relações entre os diversos grupos humanos estabelecidos na Serra Gaúcha e seus descendentes que migraram para outras regiões no Brasil e para o Paraguai.
\end{abstract}

Palavras-chave: Migração - Rio Grande do Sul. Imigrantes. Identidade Social.

\author{
Miriam de Oliveira Santos \\ Doutora em Antropologia Social pela \\ Universidade Federal do Rio de Janeiro. \\ Professora do Programa de Pós-Graduação em \\ Ciências Sociais da Universidade Federal Rural \\ do Rio de Janeiro. \\ Brasil \\ mirsantos@uol.com.br
}

\section{Para citar este artigo:}

SANTOS, Miriam de Oliveira. Reescrevendo a história: imigrantes italianos, colonos alemães, portugueses e a população brasileira no sul do Brasil. Revista Tempo e Argumento, Florianópolis, v. 9, n. 20, p. 230 - 246. jan./abr. 2017.

DOI: $10.5965 / 2175180309202017230$

http://dx.doi.org/10.5965/2175180309202017230

1 Este trabalho é parte de uma série de pesquisas que desenvolvo desde 2000 sobre a imigração história para o Brasil e suas correlações com o Tempo Presente. Ao longo desses anos fui beneficiada por financiamentos da CAPES, CNPq e FAPERJ, sem os quais o desenvolvimento e manutenção da pesquisa não teria sido possível. Uma versão preliminar de uma parte desse trabalho foi apresentada na $26^{\mathrm{a}}$. Reunião Brasileira de Antropologia, realizada entre os dias 01 e 04 de junho de 2008, Porto Seguro, Bahia, Brasil. 


\title{
Rewriting history: Italian immigrants, German colonists, Portuguese and the Brazilian population in southern Brazil
}

\begin{abstract}
We intend to understand how the creation of ethnic identities, produced by the immigration divide world between "us" and "others." We will also analyze how this "we" can be relational and at times embrace the "other" using as the descendants of the great European immigration to Rio Grande do Sul as our empirical support. As method we use ethnography and historical research, seeking the political and economic history support to understand changes in the relations between different human groups established in Serra Gaúcha and their descendants who migrated to other regions in Brasil and to Paraguay.
\end{abstract}

Keywords: Migrations - Rio Grande do Sul. Immigrants.

Social Identity.

Nosso objetivo nesse artigo é entender como as definições de identidade são relacionais ao gerar alteridades entre os imigrantes, seus descendentes e a sociedade mas também entre diferentes grupos de migrantes e imigrantes. Analisamos os confrontos entre "nós" e os "outros" produzidos pela grande imigração europeia do século XIX para também entender como esse "nós" pode ser relacional e em alguns momentos abarcar os “outros", bem como os seus reflexos no tempo presente.

A grande imigração europeia para o Rio Grande do Sul distribuiu-se espacialmente em "ilhas" de colonização, principalmente com espaços alemães e italianos mas, em menor proporção, também poloneses, franceses e judaicos. Nesse momento inicial, no final do século XIX, observamos disputas entre os chamados colonos "de origem", mas também alianças contra "brasileiros" (negros e índios) e luso-brasileiros. 
Os açorianos, nessa época não eram considerados como imigrantes, pois haviam chegado ao Brasil quando ambos países eram parte do Reino Unido de Brasil, Portugal e Algarves (1815-1822), portanto, com origem comum .

No entanto, essas diferenças tendem a ser apagadas quando esse grupo de origem imigrante muda para outros lugares do Brasil. Nesse momento, o pertencimento étnico torna-se regional pois "italianos", "alemães", "açorianos", passam a ser "gaúchos" em oposição aos demais "brasileiros". No quarto final do século XX com a imigração fronteiriça para o Paraguai ou Uruguai são chamados de "brasileiros" e no Paraguai acabam configurando um grupo conhecido como "brasiguaios" que abrange tanto os imigrantes brasileiros quanto os seus descendentes.

Analogamente ao que Renan (1992, p.23) afirma sobre o conceito de nação: “A essência de uma nação é que todos os indivíduos tenham muitas coisas em comum e que também tenham esquecido outras tantas", os grupos que estudamos também alternam suas experiências comuns e os detalhes que os diferenciam; sobretudo recorrem ao esquecimento daquilo que não lhes é relevante no momento.

Como método de trabalho, utilizamos a etnografia e a pesquisa histórica, buscando na história política e econômica, suporte para entender as transformações nas relações entre os diversos grupos humanos estabelecidos na Serra Gaúcha e seus descendentes que migraram para outras regiões no país ou fora dele.

Tais grupos não podem ser pensados como grupos étnicos, mas a literatura sobre etnicidade se ajusta ao seu estudo e permite iluminar algumas questões. O conceito que mais se adapta ao estudo de tais grupos é o de Max Weber (1981) em que o grupo não se define apenas mediante características raciais ou culturais, pensado por meio do pertencimento, definido de maneira subjetiva. Segundo Weber, o seu sentido, aparece no contato interétnico à medida em que a "solidariedade étnica" se manifesta no confronto com elementos estrangeiros em oposição ao que é diferente, a despertar, neste embate entre o "nós" e os "outros", o sentido da unidade grupal.

Ao definir o grupo étnico pela crença subjetiva numa origem comum, Weber sublinha que não é conveniente procurar a etnicidade em características fixas. Esta deve ser procurada antes na produção, manutenção e aprofundamento das diferenças, cuja 
objetividade não pode ser avaliada independente do significado que os indivíduos lhe atribuem no decorrer de suas relações sociais. Tais atividades funcionam como políticas de identidade, produzindo sinais diacríticos e marcadores sociais das diferenças.

Movimentos e políticas de identidade constituem uma presença obrigatória na contemporaneidade pois, junto com a sua prática, também surgem problemas e tensões. Basta notar, como no Sul, há diferentes afirmações de identidades: quilombolas, açorianas, italianas e alemães que se contrapõem. Por outro lado, novas identidades decorrem da fragmentação de antigas: não mais colonos alemães, mas pomeranos; não mais colonos italianos, mas trentinos ${ }^{2}$. Sendo assim. a instrumentalização política das identidades gera momentos de tensões sociais e conflitos colocados em pauta pelas reivindicações identitárias assim como pela sua manipulação-Sobretudo, como destaca Leal, as fronteiras entre identidade, xenofobia e violência que são muito frágeis. (LEAL, 2007, p.186).

Entretanto, como a própria citação de Weber lembra, é importante destacar que a reivindicação identitária não surgiu de uma hora para outra. Afinal, as identidades são construídas para a diferenciação ao refletirem a maneira pela qual o grupo reflete sobre si mesmo (HANDLER, 1984).

Contudo, como assinala Bourdieu: "O poder de impor uma visão das divisões, isto é, o poder de tornar visíveis, explícitas, as divisões sociais implícitas, é o poder político por excelência: é o poder fazer grupos, de manipular a estrutura objetiva da sociedade". (BOURDIEU, 1990, p.167). E o poder de escrever a história, ou determinar qual a verdadeira história, é também um poder político.

No caso do Rio Grande do Sul, por exemplo, é exatamente esse instrumento que permite que os açorianos se desloquem de uma identidade luso-brasileira para a categoria de imigrantes. Nesse ponto acompanho o pensamento de Barth (2000) que assinala que as fronteiras étnicas são sociais, simbólicas e mutáveis.

\footnotetext{
${ }^{2}$ É necessário ressaltar que na cidade de Caxias do Sul existem, além do Centro Cultural Ítalo-Brasileiro, o Circolo Trentino de Caxias do Sul e a Associação Vêneta de Caxias do Sul. Parece-nos que o mecanismo que opera na manutenção destas identidades regionais é o mesmo dos descendentes de italianos que preferem ser considerados "ítalo-gaúchos" e não "ítalo-brasileiros". Afinal o desenvolvimento desigual do Norte e do Sul da Itália faz com que os descendentes de Trentinos e Vênetos tenham mais "prestígio" do que genéricos “descendentes de italianos." (SANTOS, 2015)
} 


\section{A Colonização do Rio Grande do Sul}

Os colonos provenientes das Ilhas dos Açores se estabeleceram no litoral do Rio Grande do Sul e de Santa Catarina na segunda metade do século XVIII; essas colônias tinham como finalidade promover a ocupação territorial e também implementar um modelo de agricultura familiar como alternativa à grande propriedade monocultora.

No caso específico do Rio Grande do Sul, a colonização açoriana iniciou-se em janeiro de 1752 com sessenta casais que se instalaram em Porto de São Francisco dos Casais hoje, cidade de Porto Alegre. A imigração açoriana também tinha uma finalidade geopolítica e serviu para reforçar a presença portuguesa na área que entre Santa Catarina e Rio da Prata e contribuir para o predomínio da língua lusa sobre a castelhana. As colônias açorianas funcionavam como núcleos de resistência à expansão espanhola proveniente da região do Rio da Prata ${ }^{3}$.

Após a independência do Brasil, a primeira colonização maciça aconteceu no Rio Grande do Sul a partir de 1824, com imigrantes vindos da Liga Alemã (1815-1866). Nos primeiros cinquenta anos de imigração, chegaram de vinte a 28 mil alemães no Rio Grande, a quase todos voltados para o trabalho rural. Para efetivar essa colonização, em 1822, o governo brasileiro enviou o Major Schäffer à Europa para realizar propaganda e assinar acordos para viabilizar a vinda de imigrantes de língua alemã para o sul do Brasil.

Os primeiros imigrantes enviados por Schäffer desembarcaram em Porto Alegre no dia 18 de julho de 1824. Era um grupo de 39 imigrantes alemães enviados para Real Feitoria do Linho Cânhamo, então desativada, localizada na margem esquerda do Rio dos Sinos, aonde chegaram, em 25 de Julho de 1824, para povoar o vale do Rio do Sinos.

Durante a Revolução Farroupilha, a colonização foi interrompida, mas, com o final do conflito, afastaram-se do ponto de chegada e fundaram colônias nos vales dos rios Taquari, Pardo e Pardinho. No início do século XX, chegaram ao noroeste do estado, posteriormente, atravessaram o Rio Uruguai migrando para o oeste de Santa Catarina e Paraná, além de também fundarem colônias no norte da Argentina e no Paraguai.

\footnotetext{
3 Nunca é demais lembrar que no período de 1763 e 1777 o Rio Grande do Sul teve dois terços do seu território ocupado por tropas ligadas ao reino da Espanha e que segundo Kuhn, um dos objetivos da instalação dos açorianos na região era fazer de cada pai de família um soldado na luta contra os espanhóis. Afinal além de sementes, vacas e ferramentas, cada colono recebia também uma arma de fogo. (KUHN, 1999,p.100-105)
} 
Essa primeira grande colonização alterou a ocupação dos espaços do sul do Brasil e tornaram rentáveis áreas que, até então, eram economicamente desprezadas. Em uma sociedade dividida entre senhores e escravos, os colonos alemães se constituíram como uma classe de pequenos proprietários e artesãos livres.

Segundo Picollo:

O estabelecimento do núcleo colonial de São Leopoldo pelo Governo Geral em 1824 foi o marco inicial do processo colonizatório com imigrantes não-lusos no Rio Grande do Sul (...) Com a colonização estrangeira, incentivada pelos governos de D. João VI e de D. Pedro I, objetivava-se entre outros: a difusão da pequena propriedade e do trabalho livre (em contraposição à grande propriedade escravista); a ocupação de espaços (povoamento associado à defesa); o desenvolvimento da agricultura. (PICOLLO, 1998, p.464)

A colonização europeia no Rio Grande do Sul foi parte do projeto geopolítico do governo imperial brasileiro para preencher os chamados "vazios demográficos" do Sul do país, da mesma forma como anteriormente realizada com os açorianos. Após a independência, a concentração da colonização na região Sul foi uma das estratégias utilizadas para a consolidação das fronteiras. Neste contexto, os indígenas, que ocupavam aquelas terras, não eram pensados como nacionais ou brasileiros. Ou seja, a imigração no Rio Grande do Sul foi dirigida para a colonização, que por sua vez foi pensada como um processo de preenchimento de áreas economicamente não ocupadas.

Sobre o povoamento como forma de consolidação de fronteiras é interessante analisar o depoimento de um historiador local, descendente germânico:

Quando, então, terminou a revolução em 1845, o Rio Grande estava completamente arrasado, economicamente, porque a base da economia gaúcha eram as fazendas e as fazendas estavam destruídas por causa da guerra. Os fazendeiros eram os que tinham provocado a guerra e estavam destruídas. E a economia toda estava destruída. E o império temia muito por uma nova tentativa de separação do Rio Grande, porque a influência da Argentina era muito grande. O ditador Rosas, por exemplo, queria que os farrapos se aliassem a ele e tudo. Eles que não fizeram. Disseram que no momento que o primeiro argentino entrasse aqui, com o sangue deles iriam assinar a paz dos farroupilhas com o Brasil. Quer dizer, não aceitarem. Mas temia-se uma nova tentativa de separar, como Uruguai já tinha sido separado, formando um pequeno país independente. Bastava só a Inglaterra apoiar, que ia sair. Aí então, o governo imperial entendeu que era urgente povoar o Rio Grande com 
imigrantes, de modo especial os alemães, que se mantivessem fiéis ao trono, e que então povoassem aquela grande parte do Rio Grande que era completamente despovoada. Aquela parte norte/nordeste, do Rio Grande praticamente não tinha contato com o resto do império a não ser por via marítima, que aquilo tudo era mato, era índios, e coisas assim ${ }^{4}$.

Chama atenção no discurso a reafirmação da retórica oficial pios, se por um lado o entrevistado afirma que a região era despovoada, no final afirma que "aquilo era tudo mato, índios", ou seja, os nativos não eram considerados povoadores e, são associados à selva e inseridos no polo da natureza ao qual se opõe à civilização trazida pelos Imigrantes. Todavia, Roche reforça que a proposta era não só preencher vazios demográficos e econômicos, mas também a função exemplar dos colonizadores:

(...) as colônias eram fundadas para balizar e preparar a abertura das estradas que subiriam o escarpamento da serra. Invadiam a frente florestal além da zona de povoamento luso-brasileira e formavam grande número de núcleos agrícolas cujos intervalos seriam ocupados, pouco a pouco, pela população de origem nacional, que a prosperidade exemplar das colônias oficiais atrairia (ROCHE, 1969, p.112).

Além das funções estratégica e geopolítica, a imigração foi planejada como um processo de substituição não só do trabalho escravo pelo trabalho livre, mas principalmente como uma substituição do negro escravo pelo branco europeu em processo colonizador baseado na pequena propriedade. Nesta perspectiva, a escravidão era vista como forma arcaica de trabalho que não se coadunava com a modernidade, enquanto a colonização, como processo moderno e civilizatório. Cabe assinalar que a política imigratória e seus objetivos alteram-se ao longo do tempo pois, como ressalta Carneiro (1950, p.10) houve basicamente duas políticas de imigração:

(1) a política do governo imperial, criando núcleos coloniais de pequenos proprietários, num prosseguimento da velha ideia colonizadora, inaugurada por D. João VI, com a fundação de Nova Friburgo; e (2) a política dos fazendeiros, que querem imigrantes para a lavoura, à medida que vêem o braço escravo escassear.

No sul do Brasil predominou a primeira forma, enquanto que na província de São Paulo encontramos mais a segunda. Após 1850, a Lei de Terras, a propriedade fundiária

\footnotetext{
${ }^{4}$ Depoimento do diretor de um Arquivo Histórico Municipal de uma cidade de descendentes de imigrantes alemães na serra gaúcha, gravado em janeiro de 2001. Apud Santos (2015).
} 
foi transformada em mercadoria e cessou a distribuição gratuita para os imigrantes e que despertou o interesse da iniciativa privada. Assim, ao lado das colônias imperiais e provinciais foram fundadas colônias particulares (IOTTI, 2001, p.24). Sobre o impacto da Lei de Terras na colonização, Woortmann esclarece:

O processo de ocupação pelos colonos interessava ao capital num duplo sentido: a valorização das terras e a comercialização da produção. Realizando o objetivo da Lei de Terras, datada de 1850, a colonização transforma terras devolutas em mercadoria, cria um campesinato parcelar ao mesmo tempo em que elimina o posseiro (e os grupos indígenas, exterminados no bojo do processo), e transforma a propriedade no fundamento da subordinação do capital (WOORTMANN,1988, p.99).

O objetivo dos agentes de colonização era trazer para o Brasil famílias de agricultores brancos ${ }^{5}$, e o processo de recrutamento para a colonização no norte da Itália só se efetivou quando se tornou mais difícil trazer alemães, vistos como agricultores mais eficientes e como o ideal para a colonização no Rio Grande do Sul (SEYFERTH, 2001). Seyferth demonstra que, antes mesmo da imigração se efetivar, já funcionava um processo de classificação e hierarquização dos imigrantes.

A colonização com imigrantes europeus de origem não lusitana deu origem à formação de um novo tipo de campesinato no Brasil que, por sua vez, engendrou a construção de núcleos urbanos e de um pequeno mercado regional. A colonização, em forma de pequenas propriedades, reproduziu o modelo do campesinato europeu, assim como, também, seus problemas: escassez de terras e migração constante em busca de novas frentes agrícolas.

Esses camponeses europeus adquirirão ao chegar ao Rio Grande do Sul a identidade de colonos, isto é, proprietários de uma fração de terra denominada colônia. Segundo Seyferth (1993, p.38): “No seu significado mais geral, a categoria colono é usada como sinônimo de agricultor de origem europeia, e sua gênese remonta ao processo histórico de colonização (...) e ainda "A categoria colono foi construída, historicamente

\footnotetext{
5 Este aspecto fica claro, por exemplo, em uma publicação sobre o Brasil, feita para a Exposição Universal de Paris em 1889: "Encontrar-se-ão mais adiante, (...) alguns dados estatísticos sobre as três raças que compõem o povo brasileiro. Os índios e os negros de pura raça acabarão provavelmente por desaparecer numa mestiçagem geral com a raça branca, reforçada cada dia pela imigração" (LEVASSEUR, 2000, p.50).
} 
como uma identidade coletiva com múltiplas dimensões sociais e étnicas."(SEYFERTH, 1993, p.60)

Assim, a palavra colono, designação oficial para o imigrante que adquiria um lote de terra em um projeto de colonização, converteu-se em um símbolo de diferenciação étnica. Como haviam chegado primeiro ao Rio Grande do Sul, os descendentes de imigrantes alemães já haviam construído para si a imagem de pioneiros civilizadores, que depois os descendentes de italianos também vão reivindicar.

A alegação dos imigrantes italianos de que receberam terras piores que as dos colonos alemães e mesmo assim conseguiram tornar a cidade de Caxias do Sul "a pérola das colônias" 6 , remete para uma disputa com os demais colonos "de origem", conceito baseado na noção de etnia fundada na ideia de sangue 7 . Apesar disto, é possível observar que em casos de casamentos interétnicos, a preferência era pelo cônjuge “de origem”. No caso dos "luso-brasileiros", a preferência recaía sobre os de origem açoriana, pois eram vistos como os que compartilhavam do processo de colonização ${ }^{8}$. No entanto, é preciso lembrar que existem outros tipos de pertencimento que não apenas o étnico e que, nas classes mais altas os casamentos privilegiavam o a situação econômica.

Ao construírem para si o lugar do pioneiro, colonizador e civilizador, os imigrantes europeus e seus descendentes determinaram também o lugar dos demais residentes da terra, ou seja, para: negros e índios o papel de selvagens e incultos e para os descendentes de portugueses, de pessoas sem refinamento e de maneiras rudes. Preconceito expresso no apelido pelo qual são conhecidos: o “duro”, designação regional conhecido no país como "casca grossa”.

\footnotetext{
6 Em uma visita à Caxias do Sul, Júlio de Castilhos, então governador do Rio Grande do Sul, denominou-a "Pérola das Colônias".

7 Colonos “de origem” são aqueles descendentes de origem européia não portuguesa. Segundo Paulilo (1987, p.159) “Alemães e italianos são chamados de 'os de origem', como se o brasileiro não tivesse uma origem da qual pudesse se orgulhar".

8 Como todos possuem a nacionalidade brasileira há mais de um século é muito difícil conseguir dados precisos sobre o casamento entre descendentes de imigrantes. Fizemos a inferência à partir de sobrenomes, pesquisa em jornais da região e de afirmações dos nossos entrevistados. No entanto podemos afirmar que os "casamentos interétnicos" são mais comuns na zona urbana que na rural e nas classes mais altas, já que nas mesmas o condicionamento de classe é maior que o "étnico". Um bom exemplo é o do político Germano Rigotto, sua mãe é de origem portuguesa e irmã do pai do também político Pepe Vargas, mas enquanto Rigotto se afirma "italiano" Pepe Vargas reafirma suas origens lusas e omite a origem alemã de sua mãe.
} 
Durante a Segunda Guerra Mundial, ser “italiano” era uma categoria negativa, mas, a partir do final da guerra, houve uma reelaboração que aponta o imigrante italiano como civilizador, aquele que transformou a selva em cidade mediante o suor de seu rosto. A cultura "italiana” assumida como um elemento de diferenciação com uma construção histórica de uma identidade ligada a determinados comportamentos associados ao sentido de pertencimento a um grupo. Nesse caso, significava privilegiar a natureza biológica, ou seja, a descendência italiana, para justificar fenômenos sociais, inclusive o sucesso econômico de Caxias do Sul. Desse modo, a cultura adquiria um significado classificatório implicado na noção de superioridade e inferioridade, num discurso que hierarquiza as etnias, conforme Frosi (1998, p.166) assinala:

(...) O uso da fala dialetal italiana é, muitas vezes, artificial na boca de falantes urbanos. Ela não tem aí uma função de comunicação e de transmissão de cultura. Ela é usada como um instrumento para demarcar um espaço próprio, uma identidade cultural local, um perfil de determinado grupo humano ítalo-brasileiro regional.

Lazzarotto (1981), referindo-se aos trabalhadores da Metalúrgica Eberle, afirma que a relação de vizinhança entre imigrantes italianos, negros e caboclos era bem difícil. Nas suas palavras: "Este era o nome dado aos pretos: os brasileiros. Termo que trazia muito de pejorativo e muito de um racismo que o descendente italiano cultivou em favor da sua superioridade" (LAZZAROTTO, 1981, p.92).

Segundo o autor, dificilmente os negros conseguiam trabalhar na gravação ou na mecânica, considerados trabalhos mais limpos e racionais pois eram atuavam principalmente no trabalho pesado trabalho da fundição. De 1906 em diante, $\bar{j}$ apesar de serem vistos em número significativo nas fotos tiradas na fábrica, o primeiro operário negro contratado oficialmente, só aparece nos refgistros da empresa em 1943. Em 1952 Azevedo relatou que na cidade de Caxias do Sul, havia "uma linha de cor, bastante nítida, separando brancos de 'morenos', isto é, das pessoas de cor, as quais orçam cerca de 4\%" da população. Além disso, ele observava: “... uma linha de separação mais tênue, entre descendentes dos imigrantes primitivos [italianos] e brasileiros, geralmente originários de outras partes do estado e descendentes de lusos" (AZEVEDO, 1957, p.294). 
Muitos dos descendentes que reivindicam a identidade ítalo-gaúcha hoje, fazemno por acreditar que tal identidade lhes agrega valor e contribui para a sua diferenciação social. Ser ítalo-gaúcho é mais valorizado do que simplesmente ser mais um brasileiro. Além disso, a partir da inserção destes grupos nas redes sociais, as possibilidades de ascensão social ampliaram-se, uma vez que a marca ítalo-gaúcha passou a ser um diferencial que, por exemplo, permitiria acesso à cidadania italiana, trabalho no exterior, bolsas de estudo, etc (ZANINI, 1997) ${ }^{9}$. Interessa observar que a identidade reivindicada seja hifenizada pelo regional e não pelo nacional pois alguém se apresenta mais como ítalo-gaúcho, do que como ítalo-brasileiro. Além de a identidade regional gaúcha ser bem marcada, contribui o fato do gaúcho ser visto, ao menos no estado do Rio Grande do Sul, como superior ao brasileiro comum. Para Seyferth (2000), a identidade regional reporta:

(...) à região como um lugar geograficamente circunscrito está longe de refletir os sentidos da identidade regional, posto que o regionalismo constituiu-se, sobretudo, como representação (simbólica) sobre a cultura, especialmente aquelas formas subsumidas pelo rótulo do folclore - que tem a capacidade de ser, ao mesmo tempo, regional, nacional e universal conforme sua definição desde o romantismo alemão.

É importante registrar que o nacionalismo alemão se configura como uma resposta ao universalismo proposto pelo Iluminismo francês e que, nessa concepção o ideal de nação se fundamenta nos laços familiares, na unidade cultural e linguística e na comunhão de valores e visões de mundo. E por último, em uma origem comum, demonstrada na história e na literatura. Assim, os grupos estudados seriam tributários do romantismo alemão e buscariam a própria justificativa da sua existência nos seus princípios. Provavelmente porque o germanismo surge antes que o próprio Estado Alemão que só é fundado em 1871.

9 Zanini, Assis e Beneduzzi, demonstram que: "Os estados do Rio Grande do Sul e Santa Catarina, que receberam uma relevante quantidade de imigrantes europeus - maiormente italianos e alemães - entre a segunda metade do século XIX e a primeira do século XX, têm vivido de uma maneira diferente o processo de emigração que se observa no Brasil contemporâneo. Nesse sentido, o caso italiano é único, pois não somente apresenta uma ideia de cidadania marcada pelo jus sanguinis, elemento que caracteriza muitos Estados europeus, como a Alemanha ou a Espanha, mas, também, não impõe uma delimitação geracional para o reconhecimento da cidadania. Dessa forma, todo descendente de italiano (por via materna a partir de 1948) é um cidadão em potencial, devendo comprovar o vínculo direto de sangue para obter o reconhecimento de tal direito. (2015,p.123) 


\section{Gaúchos no Brasil}

No sul do Brasil, onde os imigrantes europeus instalaram-se em pequenas colônias que, embora nos parâmetros da política de colonização brasileira, buscavam reproduzir o modelo camponês europeu, o parcelamento das terras rapidamente levou à migração para novas frentes de expansão como forma de manutenção de sua identidade. Antigas colônias do nordeste do Rio Grande do Sul logo tiveram excedentes populacionais para fundar colônias no noroeste assim como no oeste de Santa Catarina e Paraná. Atualmente, encontramos gaúchos no Centro Oeste e até na região Norte acompanhando a expansão agrícola da soja. (SANTOS, 1993 e WOORTMANN, 1995).

A migração é uma estratégia para enfrentar as dificuldades de reprodução social da família vinculada à posse da terra e à constante ameaça de proletarização (rural ou urbana) decorrente da crise agrária e da modernização da agricultura que tem sido "protagonizada pelos descendentes dos pioneiros europeus, alemães e italianos, em busca de novas terras" (KAISER, 1999, p.51) atingindo números expressivos. Segundo Oliven: “... em 1980 havia aproximadamente 900.000 gaúchos vivendo fora do Rio Grande do Sul, o que equivale a 11,5\% da população do estado" (OLIVEN, 1991, p. 92).

Nesse momento, os grupos que se definiam como "italianos", "alemães", "ítalo gaúchos", "teuto-brasileiros" passam a ser "gaúchos" pois sê-lo fora do Rio Grande do Sul parece conservar e/ou passar a dar importância a hábitos e a comportamentos que, ou não tinham tanta relevância no estado de origem ou não eram considerados importantes para constituição identitária dos envolvidas. Esses hábitos geralmente fazem parte do universo do gauchismo, como frequentar Centros de Tradições Gaúchas (CTG), participar de grupos de danças tradicionalistas, ouvir música gauchesca, etc.

Sobre a identidade regional gaúcha, Haesbaert (1994) observa que ela nada tem de "natural", pois é produto de um momento social específico. É em nome desta identidade que são construídas alianças e moldados projetos econômicos. Segundo ele “Como a identidade regional nunca é apenas um produto ou resultado da criação e manipulação de uma fração da classe dominante, cabe compreender também a força de suas raízes populares" (HAESBAERT, 1988, p.91). 
Para Haesbaert (1988) a emergência da identidade regional gaúcha acontecia em um momento no qual a região da campanha sul rio-grandense perdia a hegemonia política regional para os descendentes de imigrantes da "Serra Gaúcha". Nesse contexto, houve o deslocamento do estigma do "gaúcho" como representante do Rio Grande do Sul, em função do perfil socioeconômico e de sua identidade cultural, expressa por intermédio dos CTGs. Assim, a diáspora gaúcha tem suscitado, pelo menos desde a década de 1980, reações hostis em nível local. Segundo Kaiser (1999), que estudou a migração de gaúchos no estado de Minas Gerais, o gaúcho é visto como "extremamente prepotente, arrogante", por impor a sua cultura regional. Ainda segundo Kaiser, o que torna os gaúchos diferentes em relação a outros grupos de migrantes, é o fato de que eles "têm uma diferença importante em relação à maioria dos outros grupos em estudo hoje no Brasil: pertencem ao campo sociologicamente majoritário, são dominantes dentro da organização social, têm poder político-econômico"(1999, p.150). Kaiser faz tal afirmação em relação aos gaúchos em Buritis - MG, mas ela pode ser extrapolada para outros grupos de migrantes gaúchos no Brasil e até para os que imigraram para o Paraguai.

A imagem do Brasil como nação moderna, civilizada e superior aos países vizinhos continua presente na ideologia de muitos emigrantes brasileiros que vivem no Paraguai e se confrontam com as culturas camponesas e indígenas. Eles se apresentam como "missionários" da civilização e ensinariam aos paraguaios como ser "modernos" e “trabalhadores". Os conflitos culturais entre imigrantes e paraguaios e os estereótipos construídos nesse cenário de fronteiras aumentam as tensões entre essas "comunidades nacionais"

No Paraguai, a representação dos imigrantes brasileiros como "trabalhadores", “pioneiros" e a dos paraguaios como "preguiçosos", “corruptos" e "subdesenvolvidos", simboliza assimetrias de poder entre as nações e as classes sociais. É interessante contrastar com o discurso dos descendentes de imigrantes alemães, recolhidos em entrevistas realizadas na década de 70 do século XX em Santa Catarina:

\footnotetext{
${ }^{10}$ Sobre brasileiros no Paraguai ver Sprandel (1992).
} 
Brasileiro e caboclo é a mesma coisa. Caboclo é sujo, passa a vida comendo feijão com farinha de mandioca, por isso é amarelo, barrigudinho. Caboclos vivem doentes e não gostam de trabalhar. Quase sempre são mestiços com alguma coisa (índio, negro) e vivem em casa de barro, por isso são uns Schlambuger (desqualificados) (SEYFERTH, 1990, p.159).

Ou seja, em função dos deslocamentos e das diferentes relações entre esses grupos migrantes e o Estado nacional, esses colonos passam de "italianos" e "alemães" a brasileiros, invertendo os sinais de estigma e prestígio quanto ao que é ser "brasileiro".

\section{Considerações Finais}

A identidade marca tanto distância como também aproximações e ela se constrói mediante relações, ou seja, é processual e relacional. Em comum nas distintas perspectivas sobre o conceito de identidade étnica, é a assertiva de que as distinções fornecem a base conceitual da etnicidade, vista como uma construção social de pertença; e como capital simbólico em que a identidade étnica é muito significativa para a construção das dualidades ou diferenças sociais.

Observamos o deslizamento dos conceitos pois imigrantes passam a ser migrantes e mais tarde emigrantes. Verificamos uma gradação de identidades em função da escolha entre os diversos vínculos de pertencimento de cada grupo, e como a história contribui pra criar narrativas de identidade, ao legitimar e justificar determinadas reivindicações.

Enfim, concluímos que a manutenção de fronteiras articula-se de forma ativa em conjunto de lutas culturais e disputas simbólicas por meio das quais há uma reiteração persistente das semelhanças e diferenças que separam quem está dentro e fora da fronteira étnica que, como todas as fronteiras, é mutável e permeável. 


\section{Referências}

AZEVEDO, Thales de. Materiais para o estudo da aculturação de italianos no Rio Grande do Sul. In: REUNIÃO BRASILEIRA DE ANTROPOLOGIA, II, Salvador, 1957. Anais da Reunião Brasileira de Antropologia. Salvador: Universidade da Bahia, 1957.

BARTH, Fredrik. Os grupos étnicos e suas fronteiras. Lask, Tomke (Org.) 0 guru, o iniciador e outras variações antropológicas. Rio de Janeiro: Contracapa, 2000.

BOURDIEU, Pierre. Coisas ditas. São Paulo: Brasiliense, 1990.

CARNEIRO, José Fernando. Imigração e colonização no Brasil. Rio de Janeiro: Universidade do Brasil, 1950.

FROSI, Vitalina Maria. A linguagem oral da região de colonização italiana no sul do Brasil” In: MAESTRI, Mário. Nós, os ítalo-gaúchos. 2. ed. Porto Alegre: Editora da Universidade, 1998.

HAESBAERT DA COSTA, Rogério. Latifúndio e identidade regional. Porto Alegre: Mercado Aberto, 1988.

HAESBAERT, Rogério. Ser 'gaúcho' no nordeste, Travessia, São Paulo: CEM, ano VII, n.19, maio-ago., 1994.

HANDLER, Richard. On sociocultural siscontinuity: nationalism and cultural objectification in Quebec . Current Anthropology. v.25, n. 1, 1984.

IOTTI, Luiza. Imigração e colonização: legislação de 1747 a 1915. Porto Alegre, Caxias do Sul: Assembléia Legislativa do Estado do Rio Grande do Sul: EDUCS, 2001.

KAISER, Jaksam. O Brasil dos gaúchos: etnografia sobre a diáspora gaúcha. Florianópolis: Insular, 1999.

LAZZAROTTO, Valentim. Pobres construtores de riqueza. Caxias do Sul: UCS, 1981.

LEAL, João. Cultura e identidade açoriana: o movimento açorianista em Santa Catarina. Florianópolis: Insular, 2007.

LEVASSEUR, Émile. O Brasil. Rio de Janeiro: Letras e Expressões, 2000.

KUHN, Fabio. A fronteira em movimento: relações luso-castelhanas na segunda metade do século XVIII. Estudos Ibero-Americanos: Revista da PUCRS, v. 25, p. 91-112, 1999.

OLIVEN, Ruben. A parte e o todo: a diversidade cultural no Brasil-nação. Petrópolis: Vozes, 1991. 
PAULILO, Maria Ignez Silveira. A integração no sul do Estado de Santa Catarina. 1997. Tese (Doutorado em Antropologia Social) - UFRJ- PPGAS/Museu Nacional, Rio de Janeiro, 1987.

PICCOLO, Helga (Org.). Coletânea de discursos Parlamentares da Assembléia Legislativa da Província de São Pedro do Rio Grande do Sul. Porto Alegre: Assembléia Legislativa do RS, 1998.

RENAN, Enest. Qu'est-ce qu'une nation ? Paris, London : Presses Pocket, 1992

ROCHE, Jean. A colonização alemã e o Rio Grande do Sul. Porto Alegre: Editora Globo, 1969.

SANTOS, José Vicente Tavares dos. Matuchos: exclusão e lutas. Petrópolis: Vozes, 1993.

SANTOS, Miriam de Oliveira. Bendito é o fruto: festa da uva e identidade entre os descendentes de imigrantes italianos. Rio de Janeiro: Léo Christiano Editorial, 2015.

SEYFERTH, Giralda. Imigração e cultura no Brasil. Brasília: Editora UnB, 1990.

SEYFERTH, Giralda. Identidade camponesa e identidade étnica: um estudo de caso. Anuário Antropológico 91, Rio de Janeiro: Tempo Brasileiro, p.31-63,1993

SEYFERTH, Giralda. O Regionalismo da tradição na perspectiva nacionalista: a identidade regional segundo Gilberto Freyre. In: SEMINÁRIO INTERNACIONAL NOVO MUNDO NOS TRÓPICOS, Recife, 21 a 24 mar. de 2000. Anais Seminário Novo Mundo nos trópicos.

Recife: FGF, 2000. Disponível em: <http://nmnt.fgf.org.br/artigos/o_regionalismo.html>. Acesso em:01/04/2015.

SEYFERTH, Giralda. Imigração e nacionalismo: o discurso da exclusão e a política imigratória no Brasil. In: Castro, Mary Garcia (Coord.). Migrações internacionais: contribuições para políticas. Brasília: CNPD, 2001.

SPRANDEL, Marcia Anita. Brasiguaios: conflito e identidade em fronteiras internacionais. 1992. Dissertação (Mestrado em Antropologia Social.) - UFRJ- PPGAS/ Museu Nacional, Rio de Janeiro 1992.

WEBER, Max. Economia e sociedade: fundamentos da sociologia compreensiva. Volume 1. Brasília: EdUnb,1991.

WOORTMANN, Ellen F. Colonos e Sitiantes: um estudo comparativo do parentesco e da reprodução social camponesa. 1988. Tese (Doutorado em Antropologia) - UNB, Brasília, 1988. 
WOORTMANN, Ellen. Herdeiros, parentes e compadres: colonos do sul e sitiantes do nordeste. São Paulo-Brasília: Hucitec e EdUNB, 1995.

ZANINI, Maria Catarina Chitolina. Uma nova mentalidade?. Revista Travessia, São. Paulo, Ano X, n.28, p.19-21, Maio-Ago.,1997.

ZANINI, Maria Catarina Chitolina; ASSIS, Gláucia de Oliveira e BENEDUZI, Luís Fernando. Cidadãos de direito, estrangeiros de fato: narrativas de ítalo-brasileiros(as) na Itália.

História Oral, v. 18, n. 1, p. 117-145, jan./jun. 2015. 